\title{
Expert's Consensus on Terminology of Auditory Perceptual Assessment in Voice Disorder
}

\author{
Hye Jin Lim ${ }^{1,2}$, Jeong Kyu Kim², Gyu Ho Jang ${ }^{2}$, \\ Deok Su Kim ${ }^{2}$, Chul-Hee Choi ${ }^{1}$, and Seong Hee Choi ${ }^{1}$ \\ ${ }^{1}$ Departments of Audiology and Speech-Language Pathology, ${ }^{2}$ Otorhinolaryngology-Head and Neck Surgery, \\ Daegu Catholic University, School of Medicine, Gyeongsan, Korea
}

\section{음성 장애에서 청지각적 평정 용어에 대한 전문가 일치도}

임혜진 $^{1,2} \cdot$ 김정규 $^{2} \cdot$ 장규호 $^{2} \cdot$ 김덕수 $^{2} \cdot$ 최철희 $^{1} \cdot$ 최성희 $^{1}$

대구가톨릭대학교 언어청각치료학과, ${ }^{1}$ 대구가톨릭대학교 의과대학 이비인후과학교실 ${ }^{2}$

\author{
Received August 18, 2017 \\ Revised September 7, 2017 \\ Accepted September 7, 2017 \\ Address for correspondence \\ Seong Hee Choi, PhD \\ Department of Audiology and \\ Speech-Language Pathology, \\ Daegu Catholic University, \\ School of Medicine, \\ 13-13 Hayang-ro, Hayang-eup, \\ Gyeongsan 38430, Korea \\ Tel $+82-53-850-2542$ \\ Fax $+82-53-850-2540$ \\ E-mail shgrace@cu.ac.kr
}

Background and Objectives The purpose of this study was to conduct a preliminary study to develop a standardized guideline for terminology necessary to describe auditory perception qualitatively and quantitatively in voice disorders in the Korean language.

Subjects and Method At first, a subjective questionnaire for Korean translation and definition of 25 auditory perceptual assessment terms proposed by Titze was answered by six speech-language pathologists. Secondly, a new questionnaire that was reconstructed with objective items based on the responses to the first questionnaire was completed by 14 experts who had experience on voice disorder for more than 10 years in Korea. In both questionnaires, the necessity of 32 auditory perceptual assessment terms selected from the 25 terms defined by Titze, GRBAS and CAPE-V was surveyed.

Results The consensus on the Korean translation of auditory perceptual assessment terms was moderate $(52.6 \%)$ between experts. The terms 'rough' and 'shimmer' demonstrated highest consensus of $85.7 \%$. The consensus on Korean definition of auditory perceptual assessment terms was also moderate $(61.6 \%)$. The term 'yawny' showed complete consensus $(100 \%)$. The necessity of auditory perceptual assessment terms varied with terms, but showed high consensus.

Conclusion It is necessary to develop and apply various standardized vocabulary terms for clinical evaluation so that they can express pathology and physiological characteristics during vocalization. In addition, despite the fact that there are a lot of auditory-perceptual terms, there is a lack of knowledge about voice quality terms, suggesting the need to promote and educate the developed voice quality terms.

Korean J Otorhinolaryngol-Head Neck Surg 2017;60(12):653-63

Key Words Auditory-perceptual judgment · Voice disorder · Voice quality.

\section{서 론}

음성은 말하는 개인에 대한 정보를 자연스럽게 전달하고 음

This is an Open Access article distributed under the terms of the Creative Commons Attribution Non-Commercial License (http://creativecommons.org/licenses/by-nc/4.0) which permits unrestricted non-commercial use, distribution, and reproduction in any medium, provided the original work is properly cited.
질은 화자의 신체적, 심리적, 사회적 특성을 반영해주는 주요 수단으로 사용된다. ${ }^{1)}$ 그래서 음성에 대한 평가가 중요하며, 음 성의 지각적 평가에서 중요한 측면 중에 하나가 음성의 질에 대한 정확한 판단 및 이에 대한 자료 공유 및 정보 교환이다. ${ }^{2)}$

음성 장애 관련 분야에서 음질은 좁은 의미로 정의 내릴 때, 성대의 진동에 의해 만들어진 지각적 인상으로 정의되며 
더 넓은 의미에서 음질은 호흡 시스템, 성대, 혀, 턱, 입술, 그리 고 연구개가 협응을 한 결과로 정의할 수 있으며, 생리학적 용 어로 특징을 지을 수 있다.,44

음성을 평가하는 데 있어 기계가 아무리 정확하더라도 융통 성의 부족함이 있다. 음성 샘플이 제대로 선택되지 못했다 해 도 기계는 스스로 가려낼 수 없다. 반면, 인간의 귀는 기계만 큼 정확하고 일관적일 수는 없더라도 상황과 감정에 따라 달 라질 수 있는 모든 가능성을 고려할 수 있다는 점에서 음성 평가 시 중요한 과정으로 여겨진다.)

음성 치료 전문가를 대상으로 면담을 한 연구에서, 대부분 전문가들은 $\mathrm{GRBAS}$ 를 사용하고 있으나, 잉여적 척도에 대한 문제와 그 척도 안에 수용되지 않는 특성, 즉 비정상적 음도 나 이중음도, 음도 일탈과 같은 음질을 평가하기에는 부족하 기 때문에 음질의 용어에 대한 다양화가 필요하다고 하였다. 따라서 우리나라의 음성 장애 환자들이 호소하는 내용들에 대한 포괄적 자료 수집을 한 후 이를 근거로 하여 우리나라 음성 장애 환자들에게 적절히 활용될 수 있는 형용사와 점 수 체계를 선정하여, 새로운 청지각적 검사도구를 만드는 작 업이 필요하다. ${ }^{5)}$

아직까지 국내에서는 발성 유형을 포함한 청지각적 평정에 대한 표준화된 분류 체계가 존재하지 않으며, 이를 분류하는 데 있어서 객관적으로 신뢰할 만한 기준을 찾지 못하여 수행 되지 못하는 실정이다.)

현재 국외에서 사용되는 청지각적 평가로는 일본음성언어 의학회(1975)에서 제시한 GRBAS[전반적 중증도(grade), 거친 소리(rough), 기식성(breathy), 무력성(asthenic), 쥐어짜는 소 리(strained)]가 있으나 이는 몇 가지 음질 평가에 국한되며, 미 국 언어청각임상협회(American Speech-Language Hearing Association, ASHA)(2002)에서 여러 전문가들이 개발한 Consensus Auditory-Perceptual Evaluation of Voice(CAPE-V) 는 음질뿐 아니라 음도와 강도를 포함하여 평정하도록 고안되 었고, 전반적 중증도(overall severity), 거친 소리(roughness), 기식성(breathiness), 쥐어짜는 소리(strain), 음도(pitch), 강도 (loudness), 공명(resonance), 이중음도(diplophonia), 음성 프 라이(fry), 가성발성(falsetto), 무발성(aphonia), 무력성(asthenic), 불안정한 음도(pitch instability), 떨림(tremor), 젖은 소리(wet/ gurgly)를 평가하도록 되어 있다. ${ }^{7.8)}$

한편, Titze른 장애 음성에서 나타날 수 있는 다양한 음질 을 조사하였으며, 이를 바탕으로 총 25 개의 음질 용어를 제안 하였고, 국내에서는 $\mathrm{Sim}^{2}$ 이 Titze의 음질을 20개로 수정하여 번안한 연구가 있다. 하지만 아직까지 국내의 임상 현장에서 장애 음성에 대한 음질 용어가 혼재되어 사용되고 있으며, 청 지각적 평정 용어나 용어에 대한 명확한 정의를 위한 다학제
간 전문가들의 의견 수렴이나 합의가 부재한 실정이다. ${ }^{2,10,11}$

따라서 본 연구에서는 음성 장애에서 청지각적 평정을 질적 및 양적으로 기술하는 데 필요한 다양한 용어를 정립하기 위 해 관련 전문가의 의견을 수렴하여 청지각적 평정 용어와 정의 에 대한 일치도와 청지각적 평정 용어의 필요도에 대한 연구 를 실시하였다. 본 연구는 대구가톨릭대학교 생명윤리위원회 (CUIRB-2017-0050)의 승인을 받았다.

\section{대상 및 방법}

\section{1차 예비 연구}

1 차 연구에서는 국내 장애 음성을 기술하기 위한 예비 연구 로서 문헌 검토와 현재 임상 현장에서 사용되는 자료를 바탕 으로 다양한 청지각적 용어를 찾아 설문지를 작성하였다. 1 차 설문지 구성은 $\mathrm{Titze}^{9}$ 가 제시한 25 가지 음질 용어와 각 음질 용어의 정의를 영어로 제시하였고 이에 맞는 한글 용어와 우 리말 정의에 대해 기술하도록 개방형 질문으로 설문지를 작 성하였다. 청지각적 평정 용어에 대한 문항은 Titze $\mathrm{T}^{9}$ 의 25 가지 음질 용어[aphonic, biphonic, bleat, breathy, covered, creaky, diplophonic, flutter, glottalized, hoarse, honky, jitter, nasal, pressed, pulsed(fry), resonant, rough, shimmer, strained, strohbass, tremerous, twangy, ventricular, wobble, yawny]로 구 성하였다. 1 차 설문의 응답은 5 년 이상 음성 장애 분야에 경험 있는 임상가들에게 개방형 설문조사를 시행하여 청지각적 용어에 적절하다고 생각하는 한글 용어로 번안하도록 요청 하였다. 1 차 예비 연구를 위해 음성 장애 분야에 경험이 있는 임상가 11 인에게 전화와 메일을 통해 설문에 대한 응답을 요 청하였고 이 중 6 인으로부터 자료를 얻어내었다. 응답한 참여 자는 음성 장애 분야에서 임상 경험이 5년 이상인 언어재활사 (평균 7년 \pm 2.12 )와 1 명의 음성과학자였다.

\section{2차 본 연구}

2 차 설문지는 개방형 1 차 설문조사를 재구성하였으며, 1 차 설문조사에서 응답한 Titze ${ }^{9}$ 의 25가지 음질 용어에 대한 설 문 답변을 기초로 청지각적 평정 용어의 한글 번안과 한글 정의를 답가지로 제시하여 폐쇄형 설문지로 구성하였다. 즉, 1 차 개방형 설문지에서 전문가들이 응답한 것을 바탕으로 답가지를 작성하였으며, 중복되는 응답은 답가지에서 제외시 켰고, 답가지가 하나인 경우에는 $\mathrm{Sim}^{2}$ 의 연구를 바탕으로 본 연구의 연구자들이 답가지를 추가로 제시하여 최소 2 가 지 이상의 답가지를 포함하는 폐쇄형 설문지를 구성하였다 (Appendix 1). 2차 설문조사에서 최빈도로 선택된 한글 번 역 용어와 한글 번역 정의 답가지를 선택하여 전체 응답자 
중 그 답가지를 선택한 빈도를 일치도로 정의하였다.

본 연구에서 14 명의 전문가들이 응답한 각 문항의 청지각적 평정 용어에 대한 일치도와 정의의 일치도는 다음과 같이 나타 내었다.

청지각적 평정 용어 및 정의 일치도 $(\%)=\frac{\text { 일치된 평가자 수 }}{\text { 전체 평가자 수 }} \times 100$

청지각적 평정을 위한 각 용어의 필요도는 $\mathrm{Titze}^{9)}$ 의 25 가 지 음질 용어와 GRBAS의 5가지 음질 용어(grade, rough, breathy, asthenic, strained), CAPE-V의 15 가지 음질 용어 (overall severity, roughness, breathiness, strain, pitch, loudness, diplophonia, fry, falsetto, asthenia, aphonia, pitch instability, tremor, wet/gurgly)를 포함하였으며, 중복되는 것 은 제외시켜 최종적으로 총 32 개의 청지각적 용어로 정리하 였다. 결론적으로, 2 차 설문지에 포함한 청지각적 용어는 Titze가 제시한 25가지 음질 용어에 GRBAS의 '무력성(asthenic)'을 추가하였고 CAPE-V에서는 '음도(pitch)', '강도 (loudness)', '가성(falsetto)', '불안정한 음도(pitch instability)',

Table 1. Consensus on Korean translation of auditory perceptual assessment terms between 14 experts

\begin{tabular}{|c|c|c|c|}
\hline Term & Matching & $\%$ & Ranking \\
\hline Aphonic & 7 & 50.0 & 12 \\
\hline Biphonic & 8 & 57.1 & 6 \\
\hline Bleat & 4 & 28.6 & 24 \\
\hline Breathy & 9 & 64.3 & 3 \\
\hline Covered & 7 & 50.0 & 12 \\
\hline Creaky & 6 & 42.9 & 19 \\
\hline Diplophonic & 8 & 57.1 & 6 \\
\hline Flutter & 8 & 57.1 & 6 \\
\hline Glottalized & 9 & 64.3 & 3 \\
\hline Hoarse & 5 & 35.7 & 22 \\
\hline Honky & 4 & 28.6 & 24 \\
\hline Jitter & 8 & 57.1 & 6 \\
\hline Nasal & 9 & 64.3 & 3 \\
\hline Pressed & 8 & 57.1 & 6 \\
\hline Pulsed (fry) & 7 & 50.0 & 12 \\
\hline Resonant & 8 & 57.1 & 6 \\
\hline Rough & 12 & 85.7 & 1 \\
\hline Shimmer & 12 & 85.7 & 1 \\
\hline Strained & 7 & 50.0 & 12 \\
\hline Strohbass & 7 & 50.0 & 12 \\
\hline Tremerous & 7 & 50.0 & 12 \\
\hline Twangy & 7 & 50.0 & 12 \\
\hline Ventricular & 6 & 42.9 & 19 \\
\hline Wobble & 6 & 42.9 & 19 \\
\hline Yawny & 5 & 35.7 & 22 \\
\hline Mean & 7.4 & 52.6 & \\
\hline
\end{tabular}

'진전(tremor)', '젖은 소리(wet)'를 추가하였다. 청지각적 평정 용어의 필요도는 8점 척도로 0 7점 $(0=$ 불필요한 용어, $7=$ 꼭 필요한 용어) 중 표시하도록 하였다.

2차 본 연구에서는 구글의 설문지 프로그램에서 제작하였 으며 음성 장애 관련 전문가들에게 의견을 받는 형식으로 나 누어 실시하였다. 참여자는 10 년 이상의 경력을 가진 음성 장 애 전문가(교수, 전문의, 임상가)였다. 20 인에게 전화와 메일을 통해 설문에 대한 응답을 요청하였고 이 중 14 명에게 응답을 얻었다. 참여자들은 지역별로 보았을 때, 서울 4명, 부산 4명, 광주 2 명, 대구 3 명, 충청 1 명이었다. 전문 분야별로 보았을 때, 교수는 10 년에서 21 년 사이의 경력(평균 16.8년 4.21 )이 있는 음성 장애 전공교수였으며, 전문의는 10 20년 사이에 경력(평 균 \pm )이 있는(평균 13.8년 \pm 5.52 ) 대학병원급 이비인후과 후두 음성 전문의였고, 임상가는 10 14년 사이의 경력(평균 11.4년 $\pm 5)$ 이 있는 대학병원급 음성 장애 환자들에 대한 경험이 있 는 박사이며 1 급 언어재활사였다.

Table 2. Consensus on Korean definition of auditory perceptual assessment terms between 14 experts

\begin{tabular}{|c|c|c|c|}
\hline Term & Matching & $\%$ & Ranking \\
\hline Aphonic & 10 & 71.4 & 7 \\
\hline Biponic & 7 & 50.0 & 13 \\
\hline Bleat & 7 & 50.0 & 13 \\
\hline Breathy & 7 & 50.0 & 13 \\
\hline Covered & 7 & 50.0 & 13 \\
\hline Creaky & 7 & 50.0 & 13 \\
\hline Diplophonic & 4 & 28.6 & 24 \\
\hline Flutter & 4 & 28.6 & 24 \\
\hline Glottalized & 10 & 71.4 & 7 \\
\hline Hoarse & 7 & 50.0 & 13 \\
\hline Honky & 7 & 50.0 & 13 \\
\hline Jitter & 12 & 85.7 & 4 \\
\hline Nasal & 7 & 50.0 & 13 \\
\hline Pressed & 7 & 50.0 & 13 \\
\hline Pulsed (fry) & 8 & 57.1 & 10 \\
\hline Resonant & 6 & 42.9 & 23 \\
\hline Rough & 13 & 92.9 & 2 \\
\hline Shimmer & 12 & 85.7 & 4 \\
\hline Strained & 8 & 57.1 & 10 \\
\hline Strohbass & 13 & 92.9 & 2 \\
\hline Tremerous & 12 & 85.7 & 4 \\
\hline Twangy & 8 & 57.1 & 10 \\
\hline Ventricular & 10 & 71.4 & 7 \\
\hline Wobble & 7 & 50.0 & 13 \\
\hline Yawny & 14 & 100.0 & 1 \\
\hline Mean & 8.6 & 61.1 & \\
\hline
\end{tabular}




\section{통계 방법}

청지각적 평정 용어, 정의, 필요도에 대한 신뢰도 검증 방법 이며 intra-class correlation으로 내적 일치도를 분석하였다. 내적 일치도는 Cronbach's $\alpha$ 값이 0.8 이상인 경우 내적 일치 도가 있는 것으로 판정하였다. 통계 프로그램은 SPSS 19.0 (IBM Corp., Armonk, NY, USA)을 사용하였다.

\section{결 과}

\section{청지각적 평정 용어와 용어 정의의 일치도}

높은 일치도에 따른 최종 선정된 청지각적 평정 용어와 용 어에 대한 우리말 정의는 Appendix 2와 같다.

장애 음성의 청지각적 평정 용어에 대한 최종 전문가들의 일
치도는 평균 $52.6 \%$ 였으며, 전체 $(\mathrm{n}=14)$ 가 합의되는 용어는 없 었다. 평가자 간 일치도에 대한 Cronbach's $\alpha$ 값은 0.777로 낮 은 일치도를 보였다. 그중 높은 일치율(85.7\%)을 보이는 것은 거친 소리(rough)와 진폭 변동률(shimmer)이었다(Table 1).

청지각적 평정 용어의 정의에 대해 전문가들의 일치도는 평 균 61.1\%였으며, 평가자 간 일치도에 대한 Cronbach's $\alpha$ 값은 0.573 으로 낮은 일치도를 보였다. 이 중 전체 $(\mathrm{n}=14)$ 합의를 보 이는 것은 'yawny'에 대한 정의로 '하품하면서 말하는 듯한 소리'에 전체 합의를 보였다(Table 2).

\section{청지각적 평정 용어의 필요도}

총 32가지 청지각적 평정 용어에 대해 전문가들의 필요도 에 대한 응답은 평균 5.06점이었으며, 기식성(breathy)이 6.79

Fig. 1. Necessity of auditory percep-

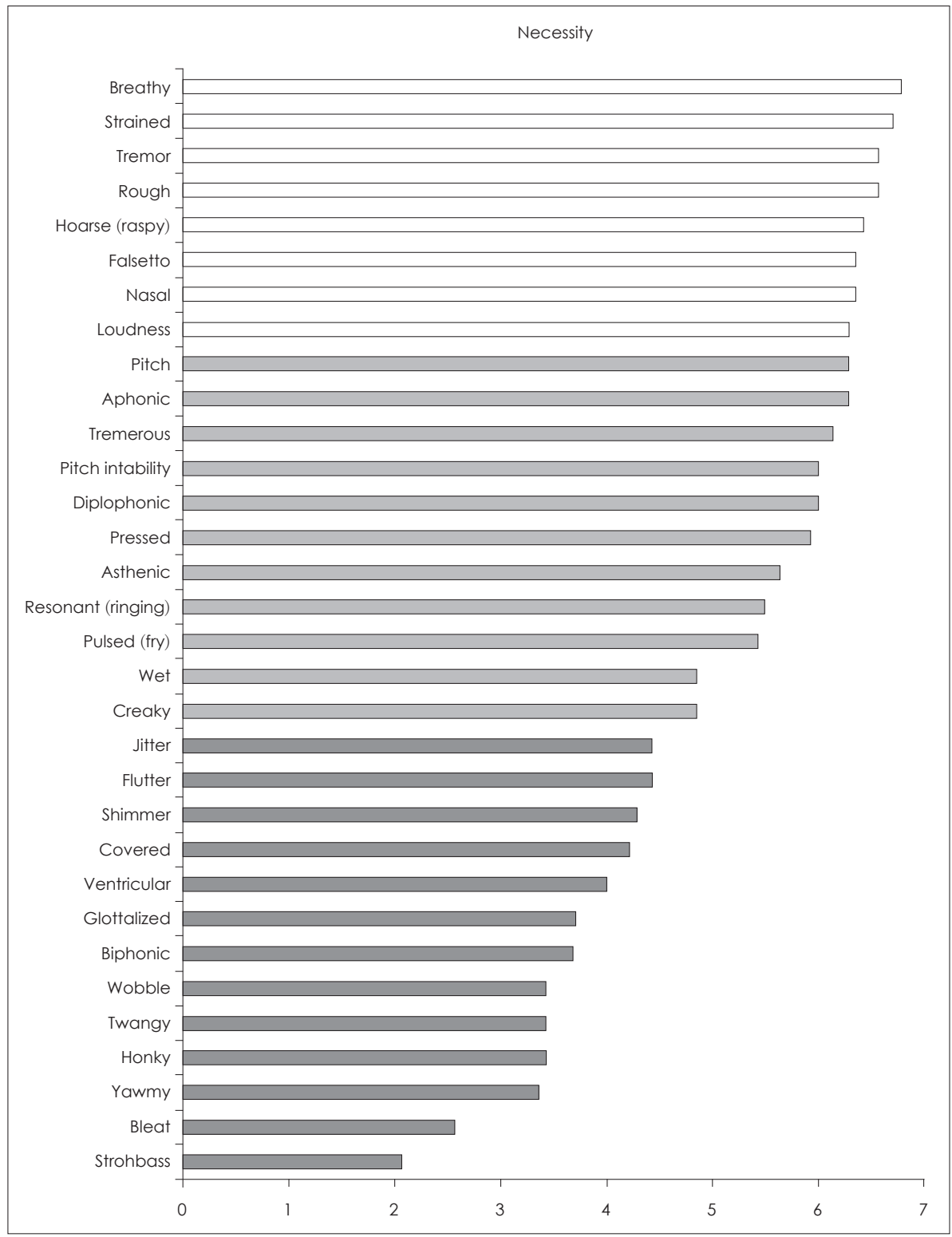
tual assessment terms. 
점, 쥐어짜는 소리(strained)가 6.71점으로 가장 높았으며, 양 울음소리(bleat)가 2.57점, 노래 중 튀기는 소리(strohbass)가 2.07점으로 가장 낮은 것으로 나타났다(Fig. 1). 필요도에 대 한 일치도 검사 결과, Cronbach's $\alpha$ 값은 0.889로 높은 일치도 를 보였다.

\section{청지각적 용어에 대한 추가 의견}

설문지의 추가적인 의견에 대한 응답을 살펴보면, 음도 일탈 (pitch break)을 4인이 제시하였고, 음성 일탈(voice/phonation break)을 3인이 제시하였다. 또한 과다비성(hypernasal), 과소 비성(hyponasal)을 2인이 제시하였다. 그 외에도 애기 음성, 유 아 음성, 단음도(monopitch), 단강도(monoloudness), 발성통 (orynophonia), 노인성 음성(presbyphonia), 음성 틱(voice tic) 이 추가로 필요하다는 의견이 있었다.

\section{고 찰}

본 연구는 음성 장애에서 청지각적 평정을 질적 및 양적으 로 기술하는 데 필요한 다양한 용어를 정립하기 위해 관련 전 문가의 의견을 수렴하여 청지각적 평정 용어에 대한 연구를 실시하였다는 것에 의의가 있다.

설문조사 결과, 전문가들의 청지각적 평정 용어에 대한 일치 율은 $52.6 \%$ 였으며, 청지각적 평정 용어의 정의에 대한 일치 율은 $61.1 \%$ 로 중간 정도의 일치를 보였다. 응답자들은 전체 적으로 청지각적 평정 용어들에 대해 생소한 부분도 있고 명 확하게 정의하기 어렵다는 경향이 많았는데 이런 이유로 인해 낮은 일치율을 나타내는 것으로 보인다.

반면, 전문가들의 청지각적 평정 용어에서 필요도는 높은 일치도를 보였다. 가장 필요도가 높은 용어는 기식성(breathy), 쥐어짜는 소리(strained), 거친 소리(rough), 떨림(tremor), 쉰 목소리(hoarse) 순으로 나타났다. 이런 결과는 성대결절과 성 대폴립과 같은 양성성대병변 환자에서 쉰 목소리, 거친 소리, 쥐어짜는 소리를 보이며, 임상 현장에서 기능성 음성 장애 환자나 후두 운동성 장애 환자들에게 주로 나타나는 음질과 도 일치하는 것으로 보인다. ${ }^{12,13)}$

전문가들의 청지각적 평정 용어에서 가장 필요도가 낮은 용어는 양 울음소리(bleat)와 노래 중 튀기는 소리(strohbass) 가 있었으며, 양 울음소리(bleat)는 가늘게 떨리는 소리(flutter) 와 같은 음질로 인식을 하는 경향을 보였다. Titze의 연구에서 도 이 두 용어가 중복적으로 사용되는 것으로 기술하고 있다. 노래 중 튀기는 소리(strohbass)는 음성 장애 환자에서는 관 찰하기 힘든 음질이기 때문에 필요도가 낮은 것으로 보인다.

청지각적 용어 중 두음도(biphonia), 이중음도(diplophonia)
는 다른 의미를 가진 음질 용어임에도 같은 음질로 인식하는 경향이 높았다. 두음도(biphonia)는 서로 독립된 2개의 음도 로 다른 방향성을 나타내는 것으로 예를 들면 몽골의 '흐미' 소리가 있다. 이중음도(diplophonia)는 음도가 두 가지로 나타 나면서 한 옥타브 아래에 있는 음들 중에서 음이 생성되는 것 으로 거친 소리를 동반한다. ${ }^{14)}$

또한 본 연구에서는 전문가들이 비성(nasal), 과도한 비성 (honky), 공명음(resonant)도 비슷한 용어로 인식하였다. 따라 서 과대 비성과 공명된 음성에 대한 변별이 필요하며 일치된 용어가 필요할 것으로 보인다.

한편, Titze가 제시한 25가지 청지각적 평정 용어 중 주파수 변동률(jitter), 진폭 변동률(shimmer)은 청지각적 용어가 아니 며, 음향학적 용어로 구별이 필요할 것으로 보인다. 아울러 본 연구에서는 기능적, 기질적, 신경학적 음성 장애를 포함한 다 양한 음성 장애 환자의 청지각적 인상을 기술하기 위한 많은 청지각적 용어가 있음에도 불구하고 국내 전문가들 간에 낮 은 인식도를 보였으며, 우리말 정의에 대해서도 낮은 일치도 를 보여 청지각적 평정 용어에 대해 전문가 합의와 체계화 정 립이 필요함을 재확인하였다.

음성 장애 환자의 음성에 대한 청지각적 평정은 환자의 음 성에 대한 정밀한 판단과 치료의 방향을 결정하는 데 중요하 다. 따라서 발성 시 병리·생리학적 특징을 잘 표현할 수 있는 다양한 음질 용어를 개발하고 임상에서 적용하는 것이 필요 하다. 또한 많은 청지각적 용어가 있음에도 불구하고 전문가 간 상이한 의견을 보여 지식이 부족하였다.

따라서 본 연구는 개발된 청지각적 평정 용어의 홍보 및 교 육이 필요함을 시사하였다. 또한 본 연구에 사용된 청지각적 용어들이 생소한 것이 많았다. 추후에는 음성 장애 환자들이 호소하는 음성적 징후(sign)에 대한 자료를 바탕으로 이러한 음성을 주관적으로 기술할 수 있는 용어에 대한 조사와 사 전적 의미에 기초하여 좀 더 한국적 실정에 맞는 어휘를 선 정해야 한다. 그리고 음도, 강도, 음질의 생리적 특성을 기술 할 수 있는 한국형 청지각적 용어의 개발 또한 필요하다.

추후에 좀 더 많은 전문가들의 협의와 실제 음성 장애 환자 들의 음성을 음질에 따라 분류하여 임상가 간 합의된 청지각 적 평정 용어의 표준화가 이루어져야 할 것이다. 4차산업 시대 에서 음성에 대한 인식이 중요해지면서 앞으로 장애 음성뿐 아니라 정상 음성과 성악가의 예술 음성까지도 기술하기 위 한 다양한 청지각적 용어의 개발과 확대가 필요하다.

\section{Acknowledgments}

We would like to thank the professors and clinicians for participating in this study. We acknowledge National Research Foundation of Korea to support this study (NRF-2013S15A8024543). 


\section{REFERENCES}

1) Laver J. The phonetic description of voice quality. 1st ed. Cambridge: Cambridge University Press; 1980.

2) Sim HS. Basic study for development of auditory perceptual training data on voice quality. In: Chung SM, editor. The Korean Society of Logopedics and Phoniatrics Semiannual. 19. Proceedings of KSLP Conference; 2003 Nov 15; Busan: The Korean Society of Logopedics and Phoniatrics;2003. p.198-9.

3) Kreiman J, Gerratt BR, Precoda K, Berke GS. Individual differences in voice quality perception. J Speech Hear Res 1992;35(3):512-20.

4) Gerratt BR, Kreiman J. Measuring vocal quality with speech synthesis. J Acoust Soc Am 2001;110(5 Pt 1):2560-6.

5) Pyo HY, Sim HS. A study for the development of Korean voice assessment model for the patients with voice disorders: a qualitative study. Speech Science 2007;14(2):7-22.

6) Seo IH, Lee OB, Lee SJ, Chung PS. Effects of motor learning guided laryngeal motor control therapy for muscle misuse dysphoria. $\mathrm{J}$ Korean Soc 2011;3(3):133-40.

7) Hirano M. Clinical examination of voice. 1st ed. NY: Springer Verlag;
1981.

8) American Speech-Language-Hearing Association. CAPE-V ASHA special interest division 3, Voice and voice disorder [cited 2017 May 24]. Available from: http://www.asha.org/uploadedFiles/members/ divs/D3CAPEVprocedures.pdf.

9) Titze IR. Principles of voice production. Englewood Cliffs: Prentice Hall;1994.

10) Kent RD, Ball MJ. Voice quality measurement. San Diego: Singular Publishing;2000.

11) National Center for Voice and Speech. Voice qualities [cited 2017 May 20]. Available from: http://www.ncvs.org/ncvs/tutorials/voiceprod/ tutorial/quality.html.

12) Lim HJ, Kim JK, Kwon DH, Park JY. The effect of vocal function exercise on voice improvement in patients with vocal nodules. J Korean Soc 2009;1(2):37-42.

13) Korean Society of Laryngology. Phoniatrics and Logopedics. 2nd ed. Seoul: Panmun education;2016. p.203-14.

14) Adachi S, Yamada M. An acoustical study of sound production in biphonic singing, Xöömij. J Acoust Soc Am 1999;105(5):2920-32. 


\section{Appendix 1}

\section{청지각적 평정 용어에 관한 설문지}

성별: (1) 남자 (2) 여자

음성 장애 치료 및 교육(연수):

근무하는 지역:

음질 용어

- 음성 장애에서 음질 용어에 필요한 정도를 필요도 칸에 8점 척도로 기술해 주십시오.

$0=$ 불필요한 용어, $7=$ 꼭 필요한 용어

- 음성 장애의 영문 용어를 적합하다고 생각하는 한글 용어와 정의에 체크하여 주십시오.

\begin{tabular}{|c|c|c|c|c|c|}
\hline & Voice quality & Perception & 필요도 & 용 어 & 의 \\
\hline \multirow{4}{*}{1} & \multirow{4}{*}{ Aphonic } & \multirow{4}{*}{$\begin{array}{l}\text { No sound or } \\
\text { a whisper }\end{array}$} & & (1) 무발성 & (1) 입과 혀는 움직이지만 목소리가 나오지 않는 것 \\
\hline & & & & (2) 실성증 & (2) 음성 장애로 음성 산출이 불가능한 상태 \\
\hline & & & & (3) 무성 & (3) 성대가 진동하지 않으며, 목소리가 없거나 속삭이는 소리 \\
\hline & & & & (4) 기타: & (4) 기타: \\
\hline \multirow{4}{*}{2} & \multirow{4}{*}{ Biphonic } & \multirow{4}{*}{$\begin{array}{c}\text { Two independent } \\
\text { pitches }\end{array}$} & & (1) 두음도 & (1) 음도가 두 개로 각각 다른 방향을 가지는 것 \\
\hline & & & & (2) 이중음도 & (2) 발성 시 두 개의 음도 산출 \\
\hline & & & & (3) 두 가지 음도 & (3) 두 가지 다른 음도가 함께 들림 \\
\hline & & & & (4) 기타: & (4) 기타: \\
\hline \multirow{5}{*}{3} & \multirow{5}{*}{ Bleat } & & & (1) 양 소리(중복) & (1) 가늘게 떨리는 소리 \\
\hline & & & & (2) 울먹이는 소리 & (2) 과긴장으로 인하여 양처럼 떨리는 소리 \\
\hline & & & & (3) 염소 소리 & (3) 기타: \\
\hline & & & & (4) 양 울음소리 & \\
\hline & & & & (5) 기타: & \\
\hline \multirow{5}{*}{4} & \multirow{5}{*}{ Breathy } & \multirow{5}{*}{$\begin{array}{c}\text { Sound of air is } \\
\text { apparent }\end{array}$} & & (1) 기식성 & (1) 발성 시 과도한 기류 방출로 기식성음이 산출됨 \\
\hline & & & & (2) 기식음 & (2) 소리의 잡음이 들리며, 성문 사이로 공기가 새는 소리 \\
\hline & & & & (3) 공기 새는 소리 & (3) 기타: \\
\hline & & & & (4) 바람 새는 소리 & \\
\hline & & & & (5) 기타: & \\
\hline \multirow{5}{*}{5} & \multirow{5}{*}{ Covered } & \multirow{5}{*}{$\begin{array}{c}\text { Muffled or } \\
\text { 'darkened' sound }\end{array}$} & & (1) 둔탁한 소리 & (1) 성대가 덮힌 듯한 소리 \\
\hline & & & & (2) 먹먹한 음 & (2) 음성이 묻혀서(덮여서) 잘 들리지 않음 \\
\hline & & & & (3) 막힌 소리 & (3) 양쪽 귀를 막고 듣는 듯한 목소리 \\
\hline & & & & (4) 기타: & (4) 막고 말하는 듯한 어두운 목소리 \\
\hline & & & & & (5) 기타: \\
\hline \multirow{6}{*}{6} & \multirow{6}{*}{ Creaky } & \multirow{6}{*}{$\begin{array}{l}\text { Sounds like two } \\
\text { hard surfaces } \\
\text { rubbing against } \\
\text { one another }\end{array}$} & & (1) 까칠한 소리 & (1) 철판에 긁는 소리 \\
\hline & & & & (2) 날카로운 소리 & (2) 음도가 급격히 떨어지며 목을 긁는 소리 \\
\hline & & & & (3) 긁는 소리 & (3) 표면이 거친 성대가 서로 마찰하는 소리 \\
\hline & & & & (4) 삐걱거리는 소리 & (4) Fry와 비슷 \\
\hline & & & & (5) 목 잠긴 소리 & (5) 기타: \\
\hline & & & & (6) 기타: & \\
\hline
\end{tabular}


Korean J Otorhinolaryngol-Head Neck Surg I 2017;60(12):653-63

\begin{tabular}{|c|c|c|c|c|c|}
\hline & Voice quality & Perception & 필요도 & 용 어 & 의 \\
\hline \multirow{5}{*}{7} & \multirow{5}{*}{ Diplophonic } & \multirow{5}{*}{$\begin{array}{l}\text { Pitch supplemented } \\
\text { with another pitch } \\
\text { one octave lower, } \\
\text { roughness usually } \\
\text { apparent }\end{array}$} & & (1) 이중음도 & (1) 음도가 두 가지로 나타나면서 같은 방향성을 가지는 소리 \\
\hline & & & & (2) 이중 음성 & (2) 발성 시 두 개의 다른 음도 산출 \\
\hline & & & & (3) 기타: & (3) Biphonic 중복 \\
\hline & & & & & (4) 기본 주파수에 대한 $1 / 2$ 배 음이 생성됨 \\
\hline & & & & & (5) 기타: \\
\hline \multirow{6}{*}{8} & \multirow{6}{*}{ Flutter } & \multirow{6}{*}{$\begin{array}{l}\text { Often called bleat } \\
\text { because it sounds } \\
\text { like a lamb's cry }\end{array}$} & & (1) 떨리는 음성 & (1) 가늘게 우는 듯한 소리 \\
\hline & & & & (2) 음성 떨림 & (2) 빠르게 떨리는 소리 \\
\hline & & & & (3) 떨리는 소리 & (3) Bleat 중복 \\
\hline & & & & (4) 염소 소리 & (4) 양이 우는 것처럼 가늘게 떨리는 소리 \\
\hline & & & & (5) 가늘게 떨리는 소리 & (5) 기타: \\
\hline & & & & (6) 기타: & \\
\hline \multirow{4}{*}{9} & \multirow{4}{*}{ Glottalized } & \multirow{4}{*}{$\begin{array}{l}\text { Clicking noise } \\
\text { heard during } \\
\text { voicing }\end{array}$} & & $\begin{array}{c}\text { (1) 성대가 막혔다 } \\
\text { 터지는 소리 }\end{array}$ & (1) 갑자기 소리가 커졌다가 작아졌다 하는 소리 \\
\hline & & & & (2) 터트리는 음성 & (2) 성대 강한 내외전으로 발생 \\
\hline & & & & (3) 성문음 & (3) 성대를 힘주어 열거나 닫는 소리 \\
\hline & & & & (4) 기타: & (4) 기타: \\
\hline \multirow{6}{*}{10} & \multirow{6}{*}{$\begin{array}{l}\text { Hoarse } \\
\text { (raspy) }\end{array}$} & \multirow{6}{*}{$\begin{array}{l}\text { Harsh, grating } \\
\text { sound }\end{array}$} & & (1) 쉰 목소리 & (1) 탁한 음질의 소리 \\
\hline & & & & (2) 애성 & (2) 성대 진동이 불규칙하고 성문에서 잡음이 나타남 \\
\hline & & & & (3) 목 쉰소리 & (3) 기타: \\
\hline & & & & (4) 쉰소리 & \\
\hline & & & & (5) 쉰 & \\
\hline & & & & (6) 기타: & \\
\hline \multirow{5}{*}{11} & \multirow{5}{*}{ Honky } & \multirow{5}{*}{ Excessive nasality } & & (1) 과도한 비성 & (1) Nasal 중복 \\
\hline & & & & (2) 과대 비성 & (2) 과도한 콧소리 \\
\hline & & & & (3) 과비성 & (3) 과도한 음향 에너지가 비강으로 가는 현상 \\
\hline & & & & (4) 콧소리 & (4) 기타: \\
\hline & & & & (5) 기타: & \\
\hline \multirow{6}{*}{12} & \multirow{6}{*}{ Jitter } & \multirow{6}{*}{ Pitch sounds rough } & & (1) 불안정한 음도 소리 & (1) 음도 변화 \\
\hline & & & & $\begin{array}{c}\text { 기본 주파수의 } \\
\text { 주기 변동률 } \\
\end{array}$ & (2) 주기에 따른 주파수의 변동, 음향학적 분석 단위 \\
\hline & & & & (3) 불규칙한 음도 소리 & (3) 기타: \\
\hline & & & & (4) 주파수 변동률 & \\
\hline & & & & (5) 지터 & \\
\hline & & & & (6) 기타: & \\
\hline \multirow{4}{*}{13} & \multirow{4}{*}{ Nasal } & & & (1) 비성 & (1) 과다한 콧소리 \\
\hline & & & & (2) 비음 & (2) Honky 중복 \\
\hline & & & & (3) 비성음 & (3) 기타: \\
\hline & & & & (4) 기타: & \\
\hline \multirow{5}{*}{14} & \multirow{5}{*}{ Pressed } & \multirow{5}{*}{$\begin{array}{l}\text { Harsh, often loud } \\
\text { (strident) quality }\end{array}$} & & (1) 억압된 소리 & (1) 목이 눌리는 소리 \\
\hline & & & & (2) 억누르는 소리 & (2) 발성 시 과도하게 쥐어짜는 음성 \\
\hline & & & & (3) 거친 소리 & (3) 꽉 누르는 소리 \\
\hline & & & & (4) 억압된 소리 & (4) 성대를 압축하여 호기류를 감소시키는 소리 \\
\hline & & & & (5) 기타: & (5) 기타: \\
\hline
\end{tabular}




\begin{tabular}{|c|c|c|c|c|c|}
\hline & Voice quality & Perception & 필요도 & 용 어 & 의 \\
\hline \multirow{5}{*}{15} & \multirow{5}{*}{ Pulsed (fry) } & \multirow{5}{*}{$\begin{array}{l}\text { Sounds similar to } \\
\text { food cooking in } \\
\text { a hot frying pan }\end{array}$} & & (1) 튀기는 소리 & (1) 튀김 소리와 같고 $70 \mathrm{~Hz}$ 이하의 소리 \\
\hline & & & & (2) 음성 프라이 & (2) 과도하게 낮은 음도로 발성 \\
\hline & & & & (3) 튀기는 소리 & (3) 톡톡 터지는 소리 \\
\hline & & & & (4) 끓는 소리 & (4) 기타: \\
\hline & & & & (5) 기타: & \\
\hline \multirow{3}{*}{16} & \multirow{3}{*}{$\begin{array}{l}\text { Resonant } \\
\text { (ringing) }\end{array}$} & \multirow{3}{*}{$\begin{array}{l}\text { Brightened or } \\
\text { 'ringing' sound } \\
\text { that carries well }\end{array}$} & & (1) 공명 & (1) 울리는 소리 \\
\hline & & & & (2) 공명음 & (2) 관찰하기 힘듦 \\
\hline & & & & (3) 기타: & (3) 기타: \\
\hline \multirow{3}{*}{17} & \multirow{3}{*}{ Rough } & \multirow{3}{*}{$\begin{array}{l}\text { Uneven, bumpy } \\
\text { sound appearing to } \\
\text { be unsteady } \\
\text { short-term, but } \\
\text { persisting over the } \\
\text { long-term }\end{array}$} & & (1) 거친 소리 & (1) 음도가 불규칙적으로 거칠게 나오는 소리 \\
\hline & & & & (2) 조조성 & (2) 성대 진동의 불규칙으로 인한 거친 발성 \\
\hline & & & & (3) 기타: & (3) 기타: \\
\hline \multirow{5}{*}{18} & \multirow{5}{*}{ Shimmer } & \multirow{5}{*}{ Crackly, buzzy } & & (1) 불안정한 강도 소리 & (1) 강도 변화 \\
\hline & & & & (2) 진폭 변동률 & (2) 주기에 따른 진폭의 변동률, 음향학적 분석 단위 \\
\hline & & & & (3) 불규칙한 강도 소리 & (3) 기타: \\
\hline & & & & (4) 쉼머 & \\
\hline & & & & (5) 기타: & \\
\hline \multirow{4}{*}{19} & \multirow{4}{*}{ Strained } & \multirow{4}{*}{$\begin{array}{c}\text { Effortfulness } \\
\text { apparent in voice, } \\
\text { hyperfunction of } \\
\text { neck muscles, } \\
\text { entire larynx may } \\
\text { compress }\end{array}$} & & (1) 쥐어짜는 소리 & (1) 과도하게 목 근육에 힘을 주는 소리 \\
\hline & & & & (2) 과긴장 발성 & (2) 과하게 쥐어짜는 소리 \\
\hline & & & & (3) 긴장된 소리 & (3) 무리하게 힘들여 짜내는 소리 \\
\hline & & & & (4) 기타: & (4) 기타: \\
\hline \multirow{4}{*}{20} & \multirow{4}{*}{ Strohbass } & \multirow{4}{*}{$\begin{array}{l}\text { Popping sound; } \\
\text { vocal fry during } \\
\text { singing }\end{array}$} & & (1) 노래 중 튀기는 소리 & (1) 관찰하기 힘듦 \\
\hline & & & & (2) 노래 중 성구 프라이 & (2) 노래하는 도중에 음성 프라이 발생 \\
\hline & & & & (3) 노래 중 프라이 & (3) 기타: \\
\hline & & & & (4) 기타: & \\
\hline \multirow{5}{*}{21} & \multirow{5}{*}{ Tremerous } & \multirow{5}{*}{$\begin{array}{l}\text { Affected by } \\
\text { trembling or } \\
\text { tremors }\end{array}$} & & (1) 떨리는 소리 & (1) 음도가 떨리는 소리 \\
\hline & & & & (2) 음성 진전 & (2) 음도 및 강도가 떨림 \\
\hline & & & & (3) 음성 떨림 & (3) 기타: \\
\hline & & & & (4) 진전 & \\
\hline & & & & (5) 기타: & \\
\hline \multirow{5}{*}{22} & \multirow{5}{*}{ Twangy } & \multirow{5}{*}{$\begin{array}{l}\text { Sharp, bright } \\
\text { sound }\end{array}$} & & (1) 과대비성 & (1) 관찰하기 힘듦 \\
\hline & & & & (2) 튀기는 소리 & (2) 날카롭게 튀기는 소리 \\
\hline & & & & $\begin{array}{l}\text { (3) 고음으로 } \\
\text { 탱탱거리는 소리 }\end{array}$ & (3) 기타: \\
\hline & & & & (4) 비성이 섞인 윙 소리 & \\
\hline & & & & (5) 기타: & \\
\hline \multirow{6}{*}{23} & \multirow{6}{*}{ Ventricular } & & & (1) 끓는 소리 & (1) Rough와 중복 \\
\hline & & & & (2) 걸걸한 소리 & $\begin{array}{l}\text { (2) 성대를 과도하게 접촉시켜 내는 발성으로 루이 암스트롱 } \\
\text { 목소리 }\end{array}$ \\
\hline & & $\begin{array}{l}\text { Very rough } \\
\text { (Louis Armstrong- }\end{array}$ & & (3) 매우 거친 음성 & (3) 진성대 대신 가성대 앞쪽을 이용하여 발성 \\
\hline & & type voice) & & (4) 무겁고 거친 소리 & (4) 기타: \\
\hline & & & & (5) 매우 거친 소리 & \\
\hline & & & & (6) 기타: & \\
\hline
\end{tabular}


Korean J Otorhinolaryngol-Head Neck Surg I 2017;60(12):653-63

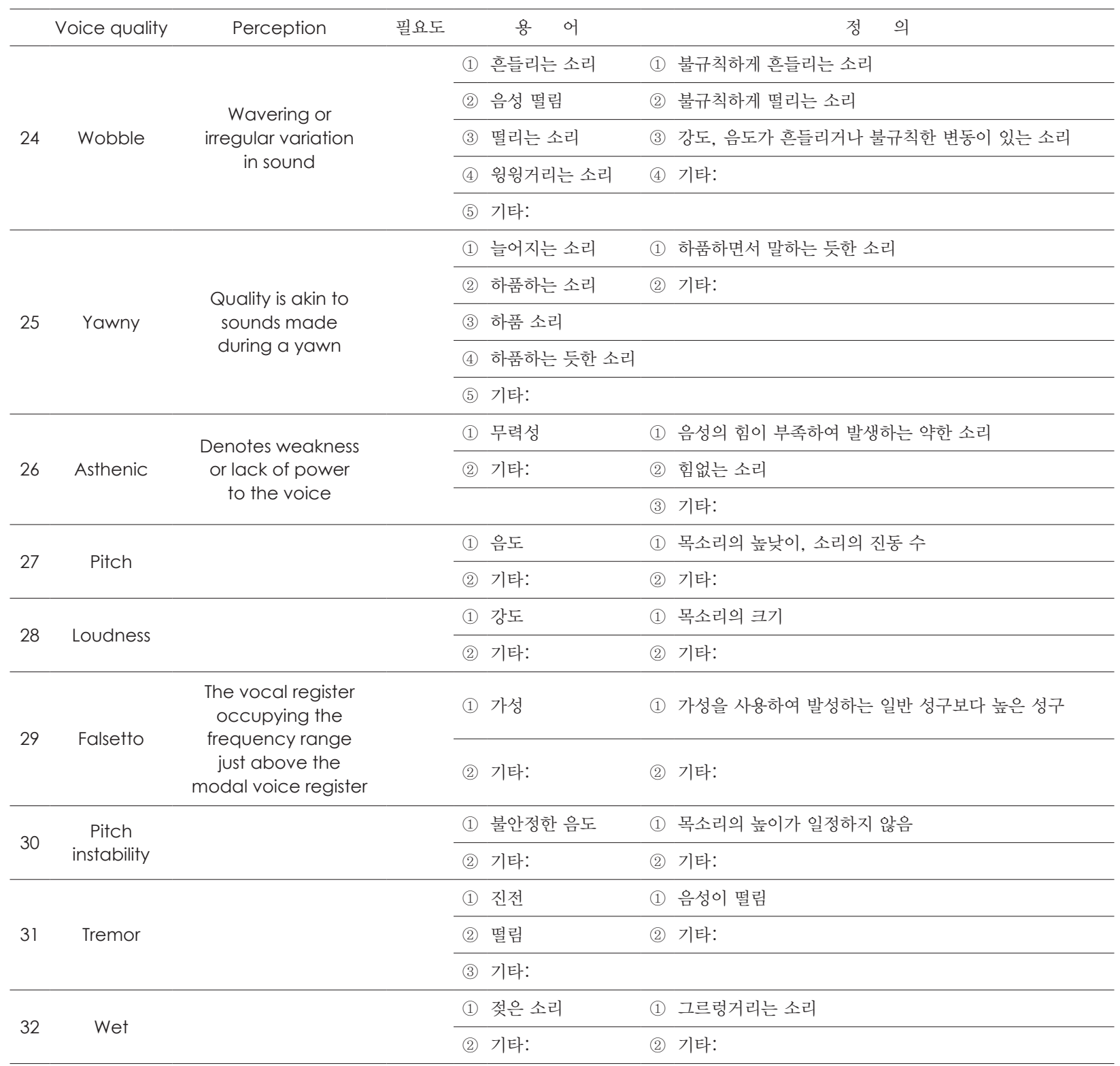

- 불필요한 용어(0점)의 이유가 무엇인지 서술해 주십시오.

- 추가로 필요한 음질 용어가 있다면 기술해 주십시오. 


\section{Appendix 2}

Korean translation and definition of auditory perceptual assessment term

\begin{tabular}{|c|c|c|}
\hline English term & Korean term & Korean definition \\
\hline Aphonic & 무발성 & 성대가 진동하지 않으며, 목소리가 없거나 속삭이는 소리 \\
\hline Biponic & 이중음도 & 발성 시 두 개의 음도 산출 \\
\hline Bleat & 양 울음소리 & 과긴장으로 인하여 양처럼 떨리는 소리 \\
\hline Breathy & 기식성 & 소리의 잡음이 들리며, 성문 사이로 공기가 새는 소리 \\
\hline Covered & 먹먹한 음 & 막고 말하는 듯한 어두운 목소리 \\
\hline Creaky & 긁는 소리 & 음도가 급격히 떨어지며 목을 긁는 소리 \\
\hline Diplophonic & 이중음도 & 음도가 두 가지로 나타나면서 같은 방향성을 가지는 소리 \\
\hline Flutter & 가늘게 떨리는 소리 & 빠르게 떨리고, bleat 중복 \\
\hline Glottalized & 성대가 막혔다 터지는 소리 & 성대를 힘주어 열거나 닫는 소리 \\
\hline Hoarse & 쉰 목소리 & 탁한 음질의 소리. 성대 진동이 불규칙하고 성문에서 잡음이 나타남 \\
\hline Honky & 과도한 비성, 과대 비성 & 과도한 음향 에너지가 비강으로 가는 현상 \\
\hline Jitter & 주파수 변동률 & 주기에 따른 주파수의 변동. 음향학적 분석 단위 \\
\hline Nasal & 비성 & 과다한 콧소리 \\
\hline Pressed & 억누르는 소리 & 발성 시 과도하게 쥐어짜는 소리 \\
\hline Pulsed (fry) & 음성 프라이 & 튀김 소리와 같고 $70 \mathrm{~Hz}$ 이하의 소리 \\
\hline Resonant & 공명음 & 울리는 소리 \\
\hline Rough & 거친 소리 & 성대 진동의 불규칙으로 인한 거친 발성 \\
\hline Shimmer & 진폭 변동률 & 주기에 따른 진폭의 변동률, 음향학적 분석 단위 \\
\hline Strained & 쥐어짜는 소리 & 과도하게 목 근육에 힘을 주는 소리 \\
\hline Strohbass & 노래 중 튀기는 소리 & 노래하는 도중에 음성 프라이 발생 \\
\hline Tremerous & 음성 떨림 & 음도 및 강도가 떨림 \\
\hline Twangy & 고음으로 탱탱거리는 소리 & 날카롭게 튀기는 소리 \\
\hline Ventricular & 무겁고 거친 소리 & 진성대 대신 가성대 앞쪽을 이용하여 발성 \\
\hline Wobble & 흔들리는 소리 & 불규칙하게 흔들리는 소리 \\
\hline Yawny & 하품하는 소리 & 하품하면서 말하는 듯한 소리 \\
\hline
\end{tabular}

